\title{
Response
}

\section{Survivors of the nations: a response to Fergusson and Pecknold}

\begin{abstract}
This paper responds to two article reviews of Democracy and Tradition ${ }^{1}-$ one by David Fergusson, the other by C. C. Pecknold. The first part of the paper seeks to clarify the author's critique of Alasdair Maclntyre and Stanley Hauerwas, in particular Maclntyre's claim that our society is inherently incapable of sustaining rational discussion and Hauerwas's conception of what 'being the church' implies. The second part defends and extends the author's account of secularization. The third part considers truth, objectivity and the relationship between philosophy and political culture.
\end{abstract}

\section{Loosing the bonds of injustice}

Alasdair MacIntyre, Stanley Hauerwas and I were drawn together in the 1970s by our shared suspicions of the political order in which we lived and of the ideologies used to defend it as a triumph of reason and freedom over tradition. With the encouragement of my new friends and mentors, I explored the implications of rejecting classical foundationalism in favor of a pragmatic conception of rational tradition. The result was my first book, The Flight from Authority, which MacIntyre and Hauerwas published in 1981 as the first volume in a series they co-edited for the University of Notre Dame Press. $^{2}$

This book argued that Descartes and his heirs, far from being the sole shapers of modern thought, represented only one modern intellectual tradition among many - the tradition according to which reason and tradition are opposed categories. The mitigated skeptics and the champions of the new probability in the middle of the seventeenth century were already in the business of saying what a tradition of rational inquiry would look like. They opposed the Cartesian quest for certainty no less than such later thinkers as Hegel, Newman, Gadamer and the American pragmatists. The modern age, I implied, is too vast and complicated to be debunked in a single stroke. In particular, the modern attempt to conduct political life in a way that avoids violent religious discord is not a wholly wretched thing. This attempt should

${ }^{1}$ Jeffrey Stout, Democracy and Tradition (Princeton: Princeton University Press, 2004).

2 Jeffrey Stout, The Flight from Authority: Religion, Morality, and the Quest for Autonomy (Notre Dame, IN: University of Notre Dame Press, 1981). 
be conflated neither with the quest for certainty nor with flight from the influence of tradition. ${ }^{3}$

When After Virtue and The Peaceable Kingdom appeared, also in the early 1980s, it became clear to me why my editors were somewhat less enthusiastic about my conclusions than I expected them to be. ${ }^{4}$ MacIntyre and Hauerwas now sometimes spoke as if liberal modernity essentially consisted in a rejection of tradition, but their main theme was that liberalism is simply mistaken in its assumption that political life can be conducted rationally and virtuously without a prior agreement on the telos of human life. To my surprise, they sometimes referred to me as a liberal, although to their credit they made clear that I did not reject reliance on tradition as such. ${ }^{5}$ At first, I was prepared to see their modernity-tradition dichotomy and their caricature of liberalism as provocative rhetorical gestures, justified by the need to get a complacent audience thinking. It was reassuring that MacIntyre and Hauerwas were sometimes willing to take back or qualify some of the claims I found dubious. I defended them against scholars who ignored the fine print. It has always been possible to interpret their views in the charitable way David Fergusson does. All you have to do is play down the initially shocking bits while playing up the qualifications. As time went on, however, I came to think that their rhetoric was actually making a bad situation worse. Let me explain how I reached this conclusion.

We survivors of the nations - survivors of the injustices that nations have visited on the poor, on slaves and their descendants, on resident aliens, and on other nations - are also citizens of nations. As such, we bear responsibility for the commissions and omissions those injustices involve, for healing the wounds they have caused, and for loosing the bonds of oppression they

3 Part two of Flight from Authority endorsed the conclusions of MacIntyre's critique of modern theology, as expressed in such works as 'The Fate of Theism', in MacIntyre and Paul Ricoeur, The Religious Significance of Atheism (New York: Columbia University Press, 1969), pp. 3-29. At that time, I was trying to rework MacIntyre's arguments against theism in light of my doubts about his epistemology. While working on the first edition of Ethics after Babel: The Languages of Morals and Their Discontents (Boston: Beacon Press, 1988), I decided that there were no philosophically sound reasons for declaring modern theistic belief rationally unjustified. Meanwhile, MacIntyre reached the same conclusion, and returned to the church. Unlike him, however, I did not come to embrace theism.

4 Alasdair MacIntyre, After Virtue: A Study in Ethical Theory, 2nd edn (Notre Dame, IN: University of Notre Dame Press, 1984; 1st edn published in 1981). Stanley Hauerwas, The Peaceable Kingdom: A Primer in Christian Ethics (Notre Dame, IN: University of Notre Dame Press, 1983).

${ }^{5}$ See especially Alasdair MacIntyre, Whose Justice? Which Rationality? (Notre Dame, IN: University of Notre Dame Press, 1988), p. 346. 
have imposed. The responsibility weighs on us. Whose burden would not be lighter without it? One important social trend in our period is a retreat from the responsibilities and disappointments of citizenship into families, friendships, local communities, lifestyle enclaves and religious communions. The retreat is understandable, because the latter relationships all hold out the promise of solace, meaning and a sense of agency to the people involved in them. These relationships are not obviously corrupted by power and money in the ways that the political economies of nation-states are, and they do not typically implicate us in horrendous evils. As identification with the civic nation weakens, however, a citizenry's sense of responsibility for the behavior of the state diminishes. The role of the citizen atrophies, thus leaving the enormous power of the state in the hands of an elite that can operate with impunity.

In my view, the demise of citizenship, though well under way, is not complete, so people who care about justice still have reason to resist it. MacIntyre and Hauerwas, however, consider it a fait accompli. The demise of citizenship, as they see it, is a byproduct of the fragmentation of ethical discourse in the modern period. Lacking agreement on the telos of human life, citizens are unable to resolve their differences through an exchange of reasons. Public discussion thus becomes a mask for the assertion of arbitrary preferences. If shared ethical deliberation in religiously diverse societies is a sham, there is no point in trying to revive a culture of citizenship in the hope of holding nation-states accountable. The only sensible course is to devote one's energy to 'the construction of local forms of community' within which the tradition of the virtues might survive the 'new dark ages which are already upon us' ${ }^{6}$

If MacIntyre's appraisal of modern ethical discourse is correct, then democratic citizenship is a lost cause, and we ought to direct our energies into other channels. If it is not correct, however, then disseminating this false view of our situation is likely to make that situation worse, because people who accept this view will have reason to behave in ways that further undercut the culture of citizenship. I therefore set out to determine whether MacIntyre was right on this point, and concluded that he was not. Our disagreement is not over how gravely unjust the current institutional order is. The dispute pertains to the question of whether democratic discursive exchange across the boundaries of enclaves committed to distinct visions of the good is an intrinsically hopeless endeavor. ${ }^{7}$ My worry is that the story MacIntyre

6 MacIntyre, After Virtue, p. 263.

7 For more along these lines, see the postscript to the Princeton edition of Jeffrey Stout, Ethics after Babel (Princeton: Princeton University Press, 2001). 
and Hauerwas have been telling is hastening the demise of citizenship at a moment when the assertion of citizenship in the wealthy democracies is the only thing that could conceivably prove capable of restraining the nation-state's exercise of arbitrary power on behalf of the ruling elite.

Recitation of the story celebrates and constitutes a counter-cultural identity for the clean of hand and heart. The narrative sets up a dramatic contrast between long-dead heroes, always kept in soft focus, and present-day villains, the barbaric liberals now in control. The crucial turning point of the story varies from one telling to the next: it might be the conversion of Constantine, the fatal errors of Scotus, the Lutheran Reformation, the rejection of Aristotelian ethics, the emergence of capitalism, the rise of the modern nation-state, or some combination of these. All versions posit some clear break from a now largely lost tradition of virtue. The story functions simultaneously to debunk the present order as virtue's opposite and to depict an existing marginalized community, also kept in soft focus, as the locus of true virtue. For Hauerwas, until recently, the recitation often included the rhetorical sacrifice of a 'liberal', whose example served as a warning to anyone disposed to question the authority of those speaking for the tradition reconstituted by the telling.

Chad Pecknold wants to know how all of this could have unwittingly done favors for right-wing politics, given that the wholesale critique of modernity being offered clearly has a left-wing pedigree as well as premodern roots. Recall that the period in which MacIntyre and Hauerwas introduced their dichotomy between tradition (understood as the sine qua non of authority and virtue) and liberal modernity (understood as essentially after virtue) is the same period in which the Reagan and Thatcher administrations adopted a remarkably similar rhetorical schema in their attempt to scale back government spending on social programs while increasing their defense budgets. The invocation of traditional virtue and the scapegoating of liberals became the order of the day for conservative politicians and the pundits defending them, but also for the rapidly emerging religious right in the United States. A growing public now obviously wanted to be told that the key to virtue was to be found in increased identification with one's local church and the relentless thrashing of liberals. This public was pleased to bracket the more disturbing implications of the 'new dark ages' story, especially its critique of capitalism. While MacIntyre and Hauerwas pointed out on a number of occasions that their conception of tradition had negative implications for right-wing ideology, their rhetoric harmonized with the language of those holding power. It is hard to imagine that right-wing politicians did not benefit from this. 
At the same time that the religious right was discovering the responsibilities and possibilities of citizenship, the young people who would have joined the civil rights movement if they had come of age in the 1960s were learning from Hauerwas that 'justice is a bad idea' and that mainline Protestantism's dedication to liberal political causes from the time of abolitionism to the time of civil rights was a form of Constantinian heresy. ${ }^{8}$ It might be that I have overestimated the influence these claims have had; my evidence is admittedly anecdotal, derived from many conversations with college students, seminarians, graduate students, professors and other Hauerwas fans over the years. While nobody doubts that he is the most influential and prolific American theologian since Reinhold Niebuhr, he protests that no theologian has enough influence these days to explain the collapse of the religious left. That may be true, but his rhetoric surely had at least a dampening effect on people who might have been able to contest the right-wing agenda more effectively on openly religious grounds. Hauerwas was prepared to say that he opposed the politics of the Republican Party, but he continued showering criticism on theologians who thought that the pursuit of justice in a liberal society could be seen as an authentic expression of Christian commitments. This, at any rate, is what many of his readers took him to be doing, which for my purposes is the issue. It should not be surprising, then, that during the same decades in which the religious right taught itself what the civil rights movement had discovered about how churches can promote political change, the churches in the USA failed to hold the government accountable for countless injustices including what amounts to the hijacking of government by the business elite.

There has been a noticeable shift in Hauerwas's rhetoric since 9/11, and he has in the meantime responded generously and flexibly to Democracy and Tradition. Most important, he has officially withdrawn his claim that justice is a bad idea. ${ }^{9}$ It is now likelier than before to find him speaking as if he himself had a share in the responsibility for the structure and policies of the government. He might well surprise us again by complicating his account of modernity and clarifying his account of the church's relationship with the world. I see nothing in his theology that should prevent him from elevating the following propositions to a more prominent position in his ecclesiology

${ }^{8}$ See especially Stanley Hauerwas, After Christendom? How the Church is to Behave if Freedom, Justice, and a Christian Nation Are Bad Ideas (Nashville, TN: Abingdon Press, 1991).

9 Stanley Hauerwas, Performing the Faith: Bonhoeffer and the Practice of Nonviolence (Grand Rapids, MI: Brazos Press, 2004), p. 231. 
than they have thus far occupied:

- That the church's prophetic mission involves declaring to the peoples of the world that they are responsible for the arrangements they have made for themselves.

- That its pastoral mission involves teaching members of the church that they are also members of families, corporations and nations and that each membership one has entails a corresponding responsibility for existing arrangements.

- That the church's members, by virtue of their multiple memberships, are also in the world and responsible for worldly arrangements.

To put the same points in Hauerwas's diction, while the church does not itself administer any arrangements other than its own, it cannot 'be the church' prophetically unless it holds the peoples of the world accountable for the behavior of nation-states, and cannot 'be the church' pastorally unless it impresses upon its own members the responsibilities entailed by their memberships in bodies distinct from the church.

Reformulating his ecclesiology to emphasize these points would have a dramatic effect on the contemporary discussion of theology and politics, because it would make clear that a proper concern for 'being the church' is perfectly compatible with Pecknold's prophetic devotion to loosing the bonds of injustice and Fergusson's interest in seeing the church as capable of adopting a simultaneously 'positive and negative relation to its host society'. The charge of Constantinianism has generated a good deal of fog. No one, as far as I can tell, has been proposing that the church directly administer the political order. There is nothing Constantinian about holding a people responsible for the condition of its government, nor about seeing it as an essential task of the church to hold its own members responsible for neglect of their responsibilities as members of nations. I have never questioned what Fergusson calls 'Hauerwas's prioritising of the church over the civic nation'. Although not a church member, I, too, have relationships that matter more to me than my membership in the civic nation. But I count on my friends to tell me when I have behaved irresponsibly. Preoccupation with the civic nation is not what Democracy and Tradition recommends. The issue is how the church and the civic nation are to be described. One hopes that the contrast between them will someday be drawn in such a way that the church's actual ethical condition is rendered visible and the civic nation can be seen as a sphere in which rational argumentation is at least possible.

My view of my own country's political situation continues to darken on a daily basis. It would only take a decision on the part of the bond markets that the government's debts are unlikely to be paid off, a consequent economic 
nosedive and a few more terrorist incidents on the scale of 9/11 to expose the fragility of American democracy. The social safety net is already in tatters. The tax code has been rewritten so as to shift burdens from the rich to the rest. The statistics on social stratification are deeply disturbing. With national security now giving rulers a standing excuse to curtail individual rights, the way has been paved for a complete destruction of political freedom, should that serve the elite's purposes under the conditions of overt social conflict that might well be realized in the coming years. If we keep heading down this path, I will myself be speaking of the new dark ages. Under such circumstances, we had better identify accurately what the source of the trouble is and determine with care whether virtuous citizenship remains a sensible, live option.

\section{What our holy cities have become}

Democracy and Tradition argues that the trouble, at least in the USA, is not that society has been secularized. I distinguish two senses of secularization. In the first, a society is secularized if its members cannot reasonably take for granted, when discussing normative questions with one another in the public square, that a particular set of answers to the most important religious questions has been accepted by the entire community. In the second sense, a society is secularized either if its central institutions are hostile to religious belief and practice, or if its members have largely stopped believing and behaving religiously. The USA is highly secularized in the first sense, but not in the second.

Secularization in the first sense is an automatic discursive effect of religious diversity. If the members of your society are committed to numerous, widely divergent religious outlooks, it makes no sense to address them as if they were religiously uniform. To resent secularization in this sense is equivalent to resenting religious diversity itself. Many people would prefer to have everybody agree with them on religious issues, but in most countries these days there is no reason to expect such agreement to be achieved.

Politics takes place in time. Decisions have to be made on a timely basis, most of them are relatively mundane, and only in some cases do our religious differences explain why we differ over what decision would be best. So for the most part, citizens of a religiously diverse society are content to leave their religious commitments out of the political discussion. This is a matter of discursive prudence. If the question before the town council is which roads to pave and the decision needs to be made before the weather turns much colder, we would be foolish to express our religious views in full and try to reach agreement on them before deciding the issue at hand. There is 
nothing residually Rawlsian about the commonsensical notion that political discourse does and should proceed much of the time without exposing the deeper disagreements of the people engaging in it. Generally speaking, if most people agree on a political proposal, no one wants to waste the public's time by tracing the proposal's possible inferential connections with each person's distinctive collateral commitments. No doubt, it would be possible, if one had the time, to show how the reasons for passing the local municipal budget cohere with the premises of Pecknold's political theology or with my theory of democratic justice, but hardly anyone bothers to make this sort of connection explicit when discussing a run-of-the-mill political issue. I have no stake in cautioning people against doing so; with a few exceptions they just don't do it. In debating most issues most of the time, people see that they will be able to advance their own political goals only if they can fashion arguments that do not take controversial premises for granted.

Not all issues, however, can be resolved so simply. For example, issues pertaining to what Kent Greenawalt calls 'borderlines of status' - whether slavery should be abolished, whether early abortions should be permitted, whether terminally comatose patients may be removed from life support, whether animals should be protected from the practices of the agricultural industry, and whether endangered species should be protected from the effects of industrial and recreational pollution - have at one time or another proven difficult or impossible to resolve on the basis of widely shared premises. ${ }^{10}$ It is hard to engage in a debate over such issues without encountering relatively deep disagreements about what has sacred value. Religious differences obviously have a bearing on issues pertaining to borderlines of status. A religiously diverse society that is not prepared to explore those differences conversationally is likely to remain at a permanent impasse when deliberating on issues of this sort.

Debates over the ethical propriety of a particular war often involve contestation among at least three claims: that all warfare is ethically impermissible, that a war can be considered just if and only if it satisfies criteria of the sort developed by thinkers like Augustine and Aquinas, and that the only thing to be taken into account is the net value of the consequences of going to war, as weighed against the consequences of alternative policies. The first two positions involve absolute prohibitions: in one case a prohibition of war as such, in the other a cluster of prohibitions, one of which rules out any intentional targeting of civilians. The absolutes essential to the first two positions impose what philosophers call side-constraints on action. The

${ }^{10}$ Kent Greenawalt, Religious Convictions and Political Choice (New York and Oxford: Oxford University Press, 1988), chapters 6-8. 
third position, in contrast, opposes all such side-constraints. Discussion of which, if any, absolute prohibitions ought to be applied to a particular war almost always brings into play premises concerning sacred value. Something has sacred value, as I am using this expression, if violating it would be horrible. The standard sort of reason for treating a prohibition as absolute is that the intentional commission of the proscribed acts would be not just bad but horrible. Most of us intuitively classify some acts as horrendous evils, and while many of us stammer when asked to explain or defend our intuitions, we do not take ourselves to be unjustified in standing firmly behind them. Theological conceptions of sacred value serve in part to make sense of these intuitions by weaving them into a comprehensive view of what matters. Attempts to inhibit the articulation of such conceptions more or less guarantee that our debates over warfare and similarly weighty issues will come grinding to a halt before the primary questions have been fully addressed.

By the same token, questions about the basic structure of society - what the primary roles are going to be and who is going to be permitted to occupy them - are hard to discuss openly without making explicit one's understanding of what kind of life is likely to make human beings, such as they are, happy and fulfilled. This is clearly a question on which religious differences have a bearing. It is no accident that the debates over birth control, divorce law and same-sex marriage have required paying a great deal of attention to our religious differences. Nor is there anything wrong with this. If we are going to overcome the impasses we sometimes reach in such debates, a more patient and conversational mode of exchange becomes necessary. That is why I encourage my fellow citizens to take justice and civility with all due seriousness and then speak their minds as they see fit, expressing whatever religious or non-religious convictions they deem relevant to their conclusions. ${ }^{11}$ There is no tension between this encouragement and the realization that most issues discussed in the political sphere are relatively shallow in nature, and require little mention of our ultimate or penultimate concerns.

What, then, of the second sense of secularization? In the USA, the entertainment industry, journalism and the educational system are sometimes said to be hostile to religious belief and practice. All this comes to, as far as I can tell, is a tendency on the part of the comparatively few atheists in the country to enter a handful of specific vocations that are focused on information and free expression. Some of these people are secularists in the sense of believing that their own institutions and disciplines, as well as the political

11 Stout, Democracy and Tradition, p. 85. 
system as a whole, should be cleansed, to the extent possible, of the effects of religious belief. Believers sometimes feel bruised or intimidated when secularist views are expressed in their presence. It is not the case, however, that American institutions are on the whole hostile to religion. The vast majority of US citizens profess belief in God. They routinely favor openly religious candidates when casting their votes, and the government inevitably reflects the religious sympathies of the majority. The separation of church and state is an institutional acknowledgment of secularization in the first sense and of the unfairness that would be involved if one set of religious commitments were privileged over other sets as a matter of governmental policy. It is not a mark of secularization in the second sense.

The example of the United States disproves the idea that secularization in the second sense is essential to either the process of modernization in general or modern democracy in particular. (India is the other most prominent counter-example.) It is therefore simply false that democratic discourse in a modern, religiously plural nation is inherently inimical to religion. Hauerwas's concerns about the democratic 'policing' of Christianity are not empirically warranted. John Milbank's account of the modern period as the emergence and triumph of 'the secular' echoes the now-discredited Weberian story, according to which modernization gradually causes religious belief to wither away, leaving the populace in an iron cage contemplating a disenchanted world. Sarah Coakley was the first to point out to me, in the spirit of Fergusson's remarks on how my views might be translated into non-American contexts, that Milbank's account looks much better if its scope of application is restricted to Western Europe. I grant, of course, that secularization in the second sense has occurred in Western Europe. This is not to say, however, that Milbankian or Weberian accounts succeed in explaining European trends, for what the counter-examples to the grand theories show is that there is no correlation between modernity and secularization in the second sense. If the accounts are going to be applied successfully to a restricted range of cases, as Fergusson suggests, somebody will have to point to a factor that is capable of accounting for the differences among various modern countries that are secularized in the first sense. It cannot be something that all of those countries have in common, such as the hospitality they show to science, technology and industry, and their tolerance of religious plurality.

Searching for such a factor is a task I happily leave to my colleagues in sociology. I see no reason, however, why my treatment of secularization in the first sense would not apply to any modern democratic republic with a religiously plural population. The local details will vary a bit, depending on whether a given country has an established church, what percentage 
of the citizens believe in God, which traditions are represented in what proportions, and whether the current situation has been shaped by a long history of inter-religious hatred and violence. Regardless of the local details, I would expect there to be a distinction between issues that are best discussed in a relatively shallow way (that is, without delving into the conflicts among comprehensive outlooks) and issues that require relatively deep exploration of religious and philosophical differences if they are to be resolved. When debate turns to issues of the second sort, I will want to give citizens of other countries the same sort of encouragement that I have given to members of my own society: love justice, cultivate the virtues of civility, and then say what you please. I have discovered no sound philosophical reason for withdrawing this advice.

There might well be societies in which the habits of civility have been so thoroughly corroded by religious strife and bigotry that expressing one's religious premises in public would qualify as rash. In such extreme circumstances, a good democrat will take care not to make things worse, while nonetheless striving to hasten the day when citizens can speak openly about their deepest concerns without fear of violent consequences. The situation Karl Barth was responding to, when drafting the Barmen Declaration, was bleak, but in a different way. He and his collaborators obviously ran personal risks by openly voicing their opposition to the Nazi regime. But by framing their condemnation in theological terms they ran no significant risk of making things worse than they already were. On the contrary, they were appealing to a large religious group, in theological terms shared by that group, to end its complicity in grave injustices. It is a pity that so few German Christians were moved by the Declaration's reasoning.

\section{Where truth stumbles}

When Isaiah denounced 'the public square' of his day as a place where 'truth stumbles', he was not making a philosophical point. What Fergusson calls 'realism' had yet to be invented, so the prophet could not have been concerned with that. His concern was with falsehoods, but he neither said, nor as far as we know thought about, what it is for a statement to be true or false. Even today, metaphysical realism is not something that most people have in mind when they complain of disregard for truth or outright lying in the public square.

Fergusson suspects, however, that the normative commitments central to a democratic culture cannot survive a widespread loss of faith in the metaethics associated with realism. This suspicion raises two distinct questions: whether realism offers successful accounts of the concept of truth and the objectivity of normative judgments and whether philosophical theories 
of this sort actually play the role in our political culture that Fergusson thinks they do. His paper does not explain what he takes realism to be. It neither argues for realism, nor tells us what to do if realism turns out to be philosophically inadequate. If realism fails philosophically, but the survival of the democratic ethos depends on belief in realism, what then? In any event, there is a danger in placing such weight on a highly controversial and rather abstruse philosophical theory. If we first persuade people that democracy depends on realism, and realism proves inadequate, we will have succeeded only in undermining commitment to democracy.

Few people concern themselves with the increasingly technical philosophical literature on truth and objectivity. We all learn to use the concept of truth as children, without being taught any philosophy, and rarely hesitate to declare an ethical or political judgment 'true' if we believe it or 'false' if we do not. That ordinary people generally treat evaluative judgments as objective is clear from their habit of holding one another responsible for those judgments. They demand reasons from one another, reasons that reflect commitment to norms. The norms possess authority by virtue of their capacity to withstand criticism over time. Ethical and political judgments involve applications of normative concepts to cases, the actual details of which must be considered and accounted for. The process of making and challenging judgments unfolds, as far as I can tell, without much help from philosophical theorizing. Of course, when people are exposed to bad philosophical argumentation, they occasionally go into a subjectivist funk, in which case additional philosophical argumentation (of a better kind) sometimes serves as an antidote. David Hume recommended a game of backgammon or some other form of relatively unreflective engagement in worldly affairs. In any period, philosophical doubts give pause to no more than a small fraction of the population, and of those, only the ones constitutionally prone to melancholy remain debilitated when they ought to be trading and assessing reasons for action.

There have been only a few historical settings in which philosophical theorizing on topics like the objectivity of normative judgments has played a crucial role in political culture. One of these settings was eighteenthcentury Scotland, where a sizable fraction of the ruling class was educated in a small handful of universities in which professors of philosophy were charged, in effect, with constructing a rational defense of the establishment's outlook. Hume wanted to be one of those professors. Everyone acknowledged the power of his intellect, but given that he did not subscribe to the establishment's moderate Presbyterianism, and had doubts about all extant attempts to make any sort of religion, revealed or natural, the basis of ethical and political deliberation, he was unable to secure the chair he 
wanted. ${ }^{12}$ Thomas Reid, who held a chair in philosophy at the University of Glasgow, was one of many Scottish intellectuals who understood that Hume's arguments required a response. To my mind, the details of his response to Hume qualify Reid as one of the great geniuses of modern philosophy. His philosophy of mind offered powerful arguments against the conception of 'ideas' that Locke and Hume had inherited from Descartes, a conception largely responsible for the least plausible aspects of Hume's empiricism and skepticism. Reid's work in epistemology introduced a vastly superior alternative to classical foundationalism. The essence of Reid's epistemology was carried into the American context - and transformed into a kind of pragmatic critical fallibilism - by the equally brilliant C. S. Peirce.

Fergusson wishes that I had said more about Reid, Pecknold that I had said more about Peirce. Reid's critique of the 'idea' idea dealt a severe blow to the philosophy of mind at work in both the rationalist and empiricist version of classical foundationalism. His objections to the notion that all beliefs are to be presumed guilty until proven innocent are reflected in Peirce's claim that one should not doubt in philosophy what one does not doubt in life. Peirce was the first great philosopher to bring together in a single synoptic vision the most important contributions of Reid, Kant and Hegel. As I see it, epistemology has made little progress since. My reason for giving Dewey more prominence than Peirce in Democracy and Tradition was that Dewey transformed Peirce's highbrow pragmatism into a philosophy of public life, a way of articulating, criticizing and improving upon the culture of democracy. For my purposes as a student of public philosophy, Dewey is the more relevant figure, because he did more than any philosopher since Emerson and Thoreau to help his fellow citizens reflect on the significance of modern democratic culture. Given that Pecknold's main interest lies in developing a pragmatic account of interpretative communities, it is easy to see why he turns primarily to Peirce for philosophical inspiration and to Peter Ochs for scholarly insight into Peirce's significance for theology. When Pecknold asks which pragmatist we should be taking seriously, I want to say: any pragmatist who helps us with projects that are worth pursuing. Why lionize one at the expense of all the others?

Fergusson's brief on Reid's behalf has to do less with his critique of the 'idea' idea or with the dangers of methodical doubt than with the truth and objectivity of value judgments. Now, if my only options in theorizing about the latter topics were Hume's position and Reid's, I would not know how to decide. They came too early to benefit from Hegel's claim that social practices

12 I once heard MacIntyre give a wonderful set of lectures on why Hume was denied entry to the professoriate. 
are responsible for shaping human beings into subjects (which for Hegel are beings appropriately held responsible for acts and judgments, rather than beings in possession of a Cartesian inner theater) and for instituting norms of objective judgment concerning the way things are, what we are obligated to do, and what is excellent, mediocre or horrible. The account of normative objectivity offered in Democracy and Tradition is an updated Hegelianpragmatic one, restated (with Robert Brandom's help) without reliance on Hegel's obscure thinking about identity or on Peirce's abstruse vocabulary of 'thirdnesses'. ${ }^{13}$ Fergusson notes that my work 'displays an overt preference for Hegel over Kant', but he does not mention that I endorse a Hegelian account of objective (socially instituted) norms. He focuses instead on my explication of truth, which he interprets as a light-minded form of Wittgensteinian therapy for mental cramps.

Peirce and Dewey were both influenced by Hegel, who gave socialpractical categories explanatory priority over the concepts of subjectivity and objectivity. ${ }^{14}$ Both saw this notion as a means of reinforcing the importance of holding ourselves responsible for the critical revision of our epistemic and ethical norms and for adjusting our beliefs appropriately in response to the objects and states of affairs we make judgments about. They did not eliminate objectivity, but rather resituated it by removing it from the context of the subject-object dichotomy and placing it in the context of social practices. Neither of them, however, offered a satisfactory account of the concept of truth, which is why they are often classified as anti-realists, despite their commitment to objective inquiry. Fortunately, in recent years a good deal of philosophical progress has been made in theorizing about truth. It turns out that realism and anti-realism, as traditionally conceived, are not the only positions available. Increasing numbers of philosophers are now drawn to a position known as minimalism, according to which ordinary truth-talk is not implicitly committed to any sort of metaphysics, realist or anti-realist. Minimalists focus on specific uses of the term 'true', the point being to show how the term in fact functions. They differentiate truth from other concepts with which it has sometimes been conflated, such as Peircean assertibility-at-the-end-of-inquiry and Deweyan warranted assertibility.

13 Robert B. Brandom, Making It Explicit: Reasoning, Representing, and Discursive Commitment (Cambridge, MA: Harvard University Press, 1994), and Tales of the Mighty Dead: Historical Essays in the Metaphysics of Intentionality (Cambridge, MA: Harvard University Press, 2002), especially chapters 6 and 7 .

14 Robert B. Brandom, 'The Pragmatist Enlightenment (and its Problematic Semantics)', European Journal of Philosophy 12/1 (2004), pp. 1-16, 6. 
Fergusson sees it as an advantage of Reid's realism that it avoids assimilating objectivity or truth to warranted assertibility, but avoidance of this conflation is also a central tenet of minimalism. One strategy the minimalist pursues while reflecting on truth is in some ways analogous to the apophatic theologian's via negativa for reflecting on divinity: by distinguishing truth from all of the concepts with which it has been confused, by saying what truth is not, one gradually rectifies one's understanding. Minimalism and apophaticism are both ways of remotion; they remove misidentifications of something. In what sense is truth an absolute notion, according to minimalism? In the sense of being non-relative: it does not involve the relativity to context that a notion like warranted assertibility or justified belief does. Minimalists are also apophatic in their wariness of saying too much about their subject matter. Treating that subject matter as a definable substance runs the risk of committing oneself to pseudo-explanations, of spouting bull. The avoidance of bull when discussing the central topics of philosophy is, as I see it, a vocational obligation of the highest order. $^{15}$

I am not certain what Fergusson means when he says that I 'make light' of the contest between realism and anti-realism. (Are apophatic theologians making light of divinity by refusing to say too much about it?) Perhaps he means simply that while I believe both realism and anti-realism to be deeply flawed, I do not find the prospect of this double failure as troubling as he would, if he were not persuaded that realism is in good shape. Why am I untroubled? My first reason is that I see in minimalism a viable alternative to realism and anti-realism. The double failure does not leave us at a loss, from my perspective. Second, and equally important, minimalism explains to my satisfaction why realism's weaknesses are unlikely to leave ordinary truth-talk, including truth-talk with respect to the application of democratic norms, in jeopardy. Hence, the weaknesses of realism do not cause me to fear for the future of democracy. I have many reasons to be troubled about the future of democracy, but this is not one of them.

Realists and anti-realists have been much better at exposing weaknesses in the other side's position than at correcting weaknesses that have been exposed in their own positions. Whenever philosophical debate reaches an impasse of this type, wise philosophers begin examining premises that both sides are taking for granted. One premise that the minimalists challenged was the idea that ordinary truth-talk is implicitly committed to a metaphysical picture. Another was the idea that an account of truth should attempt to explain, in terms more basic than the concept of truth itself, what it is for a proposition

15 See Harry Frankfurt, On Bullshit (Princeton: Princeton University Press, 2005). 
to be true. Denial of these two premises immediately brought new theoretical possibilities into view, which philosophers like Brandom, Arthur Fine, Scott Soames and Paul Horwich have been exploring ever since. But denial of the first premise had the added benefit of suggesting why the old, apparently intractable, debate over truth was less consequential than we had thought: if ordinary truth-talk is not implicitly committed to realist metaphysics, then the fate of democratic discourse probably doesn't depend on vindicating that metaphysics. Of course, if realist philosophers were to persuade the public that democratic discourse does rest on realist metaphysical assumptions, postmodernist doubts about those assumptions could still have a corrosive effect. It does not follow, however, that a defense of realism is the best way to counteract those effects.

The central claim of metaphysical realism was that true propositions are true by virtue of standing in a relation of correspondence to the real. This claim was meant to provide an explanation of what it is for a truth-bearer to be true. The main difficulty came in trying to specify what the relation of correspondence consists in while saying what antecedently differentiated proposition-shaped chunks of reality there might be for propositions to correspond to. No one knew how to differentiate the reality-chunks - the facts - without implicitly relying on the categories employed by some person or group of persons. If, however, 'correspondence to reality' is implicitly relative to mental or linguistic categories, how could one capture the realist insistence that whether a proposition is true is essentially a matter of how it is with the real, entirely apart from human descriptions and assessments of it? Persuaded that this problem could not be solved, some anti-realists claimed to find a different (idealistic) metaphysics in ordinary truth-talk, and argued that truth is coherence among one's ideas. Others proposed a fairly drastic reform of ordinary language in order to correct its basic metaphysical error (of supposing that there is more to truth than coherence). Eventually, postmodernists proclaimed the impossibility of escaping from the essentially incoherent (and, in their eyes, politically suspect) metaphysics implicit in day-to-day speech, promising instead to deconstruct and resist it from within.

The realist highlights one of the most important uses of the expression 'is true', as in: "Snow is white" is true if and only if snow is white.' Minimalists consider this use of 'true' to be perfectly in order; it establishes an equivalence pattern that contributes heavily to the term's meaning. Roughly the same equivalence pattern holds for 'corresponds to reality': "'Snow is white" corresponds to reality if and only if snow is white'. Similarly, whether one says 'The main thesis of Einstein's theory is true' or 'The main thesis of Einstein's theory corresponds to reality', one is expressing commitment 
to the main thesis of Einstein's theory. Minimalists are happy to grant, then, that 'is true' and 'corresponds to reality' are roughly synonymous in a wide range of contexts. The question is whether the notion of correspondence is capable of explaining what it is for a true proposition to be true.

Minimalists think not. Our understanding of the notion of correspondence depends on our prior practical comprehension of the notion of truth, the understanding we acquire by mastering the paradigmatic uses of 'is true' while we are growing up. Truth is obviously the more basic concept in the order of language-acquisition. When we try to explain what it is for a true proposition to be true by appealing to the notion of correspondence, we are actually trading on our prior practical understanding of the notion of truth all along. If we are content to treat the two notions as roughly similar in content, while seeing truth as a perfectly useful concept to be grasped through mastery of its paradigmatic uses, we gain some insight into how truth is related to other concepts in the same neighborhood. If, however, we begin pressing the notion of correspondence to explain what it is for a true proposition to be true, the realist's main difficulty will have to be resolved, which seems unlikely.

Why suppose, then, that a suitably reflective account of the concept of truth needs to take the form the realist theory takes - namely, that of an explanation of what Fine calls 'the substantial something' in which truth consists? ${ }^{16}$ Making this supposition gives us two choices: the reassuring realist option, which anchors truth in the world, and the disturbing antirealist option, which appears to leave us cut off from the world. Denying this supposition opens up another possibility: that what actually holds out some hope of improving our reflective understanding of the concept of truth is an explicit overview of the paradigmatic uses of 'is true' and various other expressions that are inferentially related to it in our discursive practices. Such an overview succeeds insofar as it makes explicit what is already implicit in the practical grasp of the concept we acquire by mastering its paradigmatic functions. Our practical grasp of the concept appears to be as firm as can be. What philosophy can add to this is a reflective understanding of that in which the practical grasp of the concept consists. A fully explicit account of the concept of truth specifies its meaning by describing its characteristic inferential roles. If realists and anti-realists want more than this from a philosophical account of truth, they need to say what it is they want, why they want it, and by what means they propose to supply it.

${ }^{16}$ Arthur Fine, The Shaky Game (Chicago: University of Chicago Press, 1986), chapters 7 and 8 . 
The realist worry, at this point in the discussion, will surely be that a pragmatic emphasis on explicating the uses of 'is true' and, more generally, on the social practices in which human beings master the various other moves that turn them into truth-claiming, reason-trading loci of agency and responsibility still leaves us cut off from the world, that pragmatism is really nothing more than a socio-linguistic variant of anti-realism. The pragmatic response to this worry denies that social practices are to be understood in this context as having been built up through an aggregation of interacting Cartesian subjects, defined as beings capable of immediate access to their own propositional attitudes before interacting discursively with other human beings.

To become a subject, according to the pragmatist, is to become integrated into social practices in which participants hold one another responsible for their actions and judgments. It is to become one among other loci of responsibility. The process of holding one another responsible is not a form of interaction that can be achieved by disembodied minds, communicating telepathically. The subjects engaged in the process are embodied beings, interacting not only with one another as language users, but also with other physical objects. Given that the practices being participated in involve perception and action, and given that the content of the concepts employed in the practices is determined in part by their application in perceptual judgments and intentional acts, the practices cannot be fully specified without making reference to multiple human beings interacting with one another and with non-human objects. If that is so, however, the social practices of which the pragmatist speaks are essentially in and of the world, not cut off from it. $^{17}$

It remains the case, however, that in describing or assessing anything, including the discursive social practices our group engages in, we necessarily rely on those social practices. This might sound like a disturbing limitation, but it is not. We would not be better off without relying on some set of social practices, for in that condition, we would not be capable of entertaining any claims at all. Our social practices include ample resources for self-criticism and discovery. One thing we can discover by engaging in our social practices is that some of our current commitments are in conflict and need to be revised. By engaging in observation, experimentation and scholarly research, we can deliberately cause trouble for whatever false assumptions we might be making. Meanwhile, the practices of history and anthropology can call previously unfamiliar social practices to our attention, thus allowing us to imitate or appropriate whatever features of those practices prove superior to

17 Brandom, Making It Explicit, pp. 330-3, 631-2. 
our own. And by using the powers of imagination and innovation that our current practices place in our hands, we can make claims, draw inferences, fashion concepts, experience types of emotion and perform types of action that have never been dreamt of before. Judging from the history of our practices up until now, it is clear that our practices allow us to initiate intellectual and practical changes that are revolutionary in scope, requiring us on occasion to spend generations reckoning the implications. At the end of the day, the practices will still be ours, because we will still be the ones engaging in them, but that is hardly a matter of being cut off from the world, trapped within a static, purely linguistic scheme, condemned merely to retrace forever the conceptual paths our ancestors bequeathed to us. It is rather a matter of moving about in the world, informed and enabled, but not rigidly bound, by their precedents.

Thus far, I have been using the term 'realism' to designate a metaphysically ambitious attempt to flesh out the notion of 'correspondence to reality' so that it can explain what it is for a proposition to be true. It now needs to be said that the term 'realism' has been defined in many ways and I am not certain how Fergusson intends it to be taken. As a minimalist, I affirm the idea that it is true that $P$ if and only if $P$, because this idea aptly codifies such examples of acceptable usage as: 'It is true that snow is white if and only if snow is white'. As a participant in social practices involving inquiry, I take myself generally to be trying, at least with respect to important questions whose answers are cognitively accessible to me, to believe that $\mathrm{P}$ if and only if P. $^{18}$ If all Fergusson has in mind by 'realism' is the endorsement of this cognitive goal, then I am a realist in his sense. My 'realist' attitude applies no less to ethical inquiry than to inquiry into the color or the molecular structure of a particular sample of snow.

One problem with pressing the notion of correspondence too hard, in the hope of providing an explanation of truth, is that 'corresponds to reality' is an expression that usually turns up only in contexts of ordinary observation or empirical inquiry. If Sam predicts that the snow in his driveway is white, but it turns out, when inspected carefully in brilliant sunlight, to have been turned charcoal-gray by soot, then Sam's claim about the snow is false. The snow in his driveway, to which his claim refers, is either white, as Sam claims, or not. If I examine the sooty snow in his driveway, I might say: 'You were wrong', or 'What you said isn't true'. If I say to Sam, 'Your remark

18 The importance of the qualification beginning with the phrase 'at least' is explained in Mark Johnston, 'Objectivity Refigured: Pragmatism without Verficationism', in Reality, Representation and Projection, ed. John Haldane and Crispin Wright (Oxford and New York: Oxford University Press, 1993), pp. 85-130, especially pp. 97 and 112. 
about the snow did not correspond to the facts', he might wonder why I didn't put my point more simply, but he would probably understand what I meant.

Suppose, however, that he and I are debating George on the ethics of taxation. George claims that taxing the estate of a billionaire before distributing the remainder of the estate according to the billionaire's will is inherently unjust. I might respond by saying: 'You're wrong', or 'Your position on the estate tax isn't true', thus indicating the material incompatibility of his position with mine and implying denial of his position and endorsement of mine. But if I went on to say that his remarks about the ethics of taxation 'did not correspond to reality', this would be odd, unless I meant that George had inferred his normative conclusion from false factual claims. We often use the terms 'true' and 'false' in connection with normative claims, but we rarely employ the notion of correspondence in such contexts. The metaphysical realist has a hard enough time fleshing out what it might mean for a factual judgment to correspond to the empirical facts (without relying surreptitiously on the notion that the judgment is true). But if truth is to be explained as correspondence to reality, and ethical judgments are candidates for truth and falsity, then what is it that ethical judgments are supposed to correspond to?

Fergusson might want to argue that theism provides a way of identifying the proposition-shaped chunks of reality that realism casts in the role of truth-makers. The empirical facts might be said to comprise everything in the physical world as understood from the vantage of the Creator. The actual structure of factual reality, then, is that which God had in mind when bringing the world into being. Taking this much for granted, the realist could go on to claim that true factual judgments correspond (in some sense that still requires explanation) to the details of that instantiated structure. ${ }^{19}$ If it can be assumed that God not only created the world in accordance with an overall conception of created things, but also created human beings with certain ends in view and subsequently issued a comprehensive set of commands for them to follow, then true ethical judgments can be said to correspond to the divine law implicit in God's ends and made explicit in his commands. I take it that this is approximately what Fergusson means by 'the standard meta-ethical claims' associated with 'the older pieties of family, virtue and religious community'.

Everyone theorizes from their own point of view, relying on whatever collateral assumptions they happen to have made. Thinkers who accept the picture of divine order and divine commands just mentioned are free, of

19 See Johnston, ‘Objectivity Refigured’, pp. 85-6. 
course, to develop a meta-ethical theory that makes use of that picture. They should not imagine, however, that people uncommitted to that picture are generally incapable of seeing normative judgments as candidates for truth and falsity. It is true that people who have been raised to accept that picture are sometimes sent spinning into nihilism when they acquire doubts about the picture's plausibility. If they have been taught that true ethical judgments are true only by virtue of corresponding to God's plan and commands, but cannot any longer bring themselves to believe that a Creator could be both worthy of worship and causally responsible for a world as riddled with horrors as ours is, they might wonder whether there is anything suitably solid for ethical judgments to correspond to. This thought can cause a person's moral world to come unhinged. I have no doubt that there are people struggling to live with despair and disorientation caused by this thought. Such people remain halfway committed to a theistic outlook; they believe 'the standard metaethical claims' of the correspondence theory, but not in the God presupposed by those claims. So they feel compelled to conclude that ethical judgments have nothing to correspond to, nothing of which to be true.

When theologians imagine themselves without belief in God, this is the sad spiritual condition they often have in mind: there, but for the grace of God, go I. Yet this is not what life is like for the vast majority of nonbelievers. Meta-ethical claims do not play a prominent role in the lives of most people, believers or nonbelievers. Reid's context was unusual. Only rarely does much hang, at the societal level, on finding an effective response to philosophically induced doubts about truth and objectivity. Theorists of truth and objectivity are nearly always marginal figures, to whom few people pay any attention at all; the same is true of meta-ethicists. Most people learn how to engage in the practice of ethical evaluation without assistance from meta-ethics, so the collapse of a philosophical system does not concern them. They have a practical handle on how the relevant words work and little inclination to theorize about the senses in which their judgments might be objective or subjective. Nowadays, if they hear you theorizing about "correspondence to reality' or deconstructing the 'metaphysics of presence' that supposedly pervades ordinary truth-talk, they are inclined to suspect you of being some kind of egghead or snob.

Few nonbelievers are operating with a worldview that has a giant hole in it, where God used to be. They have acquired commitments on various sorts of topics, including what is going on in the world around them, what human beings are like, whether certain acts are ethically proper, who the great exemplars of virtue have been, what sorts of episodes qualify as horrific, and what policies the government ought to adopt. They adjust these commitments in light of what they experience and what they discover by 
demanding and offering reasons to one another. In their eyes, it is true that a sunset on a clear day in the Hebrides is more beautiful than a garbage dump in Glasgow, but false that participating in genocide and caring for the survivors of torture and rape are acts equally deserving of our approbation.

They accept these things because they have been raised in a community that has applied an assortment of normative concepts to cases over time. Past applications of these concepts exert precedential authority (albeit defeasible authority) over present applications, and the present generation's judgments will be adjudicated in turn by the next generation (again, defeasibly and with no guarantee of truth). ${ }^{20}$ Most cases pose little difficulty and generate little controversy, because the tradition recognizes some sorts of considerations as more or less definitive reasons for acting in a certain way or for admiring a certain sort of person. Our reasons for condemning one action or person as cowardly or cruel exert no less force on us than our reasons for taking animals but not rocks to be living things. Of course, ethical dilemmas sometimes arise, just as anomalies do in a scientific discipline, leaving people puzzled about how to respond to a situation in which two or more inherited norms seem to point in opposite directions. In such moments nonbelievers can at least rest assured that theists have not been spared the same bewilderment everyone else experiences.

Viewed from one angle, the non-theistic pragmatist and the covenantal theologian are telling variants of the same story about how norms arise and function. They both see norms as creatures of social practices. They both see the practices as a context in which persons make commitments for which other persons hold them responsible. The activities of making commitments and holding one another responsible give rise, implicitly or explicitly, to norms. The norms instituted by a social practice constrain anyone participating in the practice. They also authorize the participants to apply the normative concepts of the practice to cases or situations that arise. Each of us is expected, when making judgments, to pay attention to previous applications of those concepts. In turn, we expect our applications of those concepts to be judged correct or incorrect by present and future participants in the practice.

The main difference between the two variants of this story is, of course, over whether the God in whose name Isaiah claimed to speak is among the persons involved in our norm-instituting evaluative practices, initiating and sustaining them in covenant with human beings, and ultimately judging them. That is a very important difference, but it should not be allowed to

${ }^{20}$ Brandom, Tales of the Mighty Dead, pp. 230-4. 
obscure the parallels between the theistic and non-theistic versions of the story. Once the parallels are brought to our attention, it should be easier to see the transition from the theism of Reid and Peirce to the non-theistic pragmatism of Dewey as one that occurs within a single, pluralistic tradition of inquiry. The continuing dispute between the theistic and non-theistic strands of this tradition has more to do with which sorts of persons there are - and thus to whom we are ultimately responsible when we tell lies in the public square or misbehave in other ways - than with whether normative judgments can aspire to truth or succeed in constraining us. It is true that theism makes a sizable difference to a person's self-understanding, but not necessarily one that has much to do with theories of truth and objectivity.

Nobody knows what would happen to the moral inheritance of humankind if theism gradually died out. If we compare attitudes toward taxation, health care and militarism in the largely Christian USA and the countries of Western Europe, which are now largely populated by nonbelievers, it is hardly clear that decline in theistic belief correlates with moral insensitivity to the poor, the infirm and the weak. When we survey what officially theistic and atheistic movements have contributed to modern life, there are so many horrors and indecencies on both sides that it would be foolish for anyone to cast the first stone. The only hope of mitigating such horrors and indecencies in the future is for believers and nonbelievers of good will to join forces wherever possible to insist on holding the rulers of their nations responsible for every horror and indecency they commit. The civil rights movement in the USA and the Solidarity movement in Poland are good models of the sort of cooperation I am recommending.

I have, in titling this essay and its three parts, alluded repeatedly to the Book of Isaiah. It is a book whose inspiring denunciations of injustice and expressions of concern for the oppressed did much to shape my moral sensibility when I was young. As I grew older, I became increasingly disturbed, however, by Isaiah's certainty that he was speaking the Word of God and by his fantasies of divine vengeance against God's alleged enemies. I cannot help thinking that many of my fellow citizens are thinking of nonbelievers like me when they endorse such fantasies as the Word of God. The passages elsewhere in the Bible where God appears to authorize the commission of genocide against those who get in the way of God's chosen people raise even more pressing questions. A politics of the Word can be as uplifting as the Barmen Declaration or as wretched as the sermons that excused the obliteration of indigenous peoples in North America as a consequence of manifest destiny. My point is not that we would be better off, on balance, if no one injected the Bible into public discussion. The Bible is 
already involved in public discussion, and is likely to remain involved for the foreseeable future. Believers have a right to express their views about what it implies for our common life. As I see it, we all benefit when citizens feel free to express the premises of their political reasoning publicly. If those premises are derived from biblical religion, so be it. Let us hear what they are, and then let us see what we learn by demanding reasons for them. The result is likely to be mixed, but why wouldn't it be? There is no political community in recorded history whose practical deliberations have not produced mixed results. Every political culture has its dangers. Vigilance is the first obligation of citizenship.

One of the things for which human beings should be held responsible - in the religious domain no less than in the political - is whom, if anyone, they choose to worship and obey. Religious convictions have political implications. Those who assert such convictions as reasons for political conclusions had better be prepared to be held accountable for what they say and believe. If, as theists claim, we all owe the true God worship and obedience as debts of justice, then we must all be in a position to ask who, if anyone, actually merits the title of 'God'. On pain of vicious circularity, this question must be posed and answered, at least provisionally, without presupposing a settled view of God's identity. Meriting application of the title 'God' and being worthy of worship and obedience cannot, at this crucial point in one's reasoning, be defined in terms of conformity to divine plans and commands. Before one can appeal to those plans and commands as a criterion, one must be capable of identifying divinity, of justly applying and withholding the title 'God'. It is appropriate, even imperative, to ask hard questions of each citizen who proposes a candidate for this title. But no person for whom theism is a live option can avoid asking such questions of him or herself, if idolatry is in fact a sin. Coherent application of the concepts of justice, merit and worthiness must, then, be possible without already taking for granted who, if anyone, is divine and which sets of plans and commands, if any, ultimately determine the content of our obligations. Otherwise, theists would be incapable of identifying the true God as God, thereby getting their theological reasoning going. Whose plan and commands are we supposed to follow? This question looms large in both religion and politics.

Its importance in the logic of idolatry-avoidance shows that theists and nonbelievers are in the same boat, conceptually speaking, at least at this one point. It is not only nonbelievers, but also intellectually responsible theists, then, who must do some of their normative thinking without merely reposing on what Fergusson calls 'strong metaphysical commitments about God'. If thinking from a non-theological point of view about important 
questions of justice is intrinsically incoherent, then theists cannot coherently do the questioning that is essential to the avoidance of idolatry. If the charge of incoherence applies to the nonbeliever, it applies to the theist as well. It would be wise to drop the charge, and grant that what the theist does with the concepts of merit and justice while trying to avoid submission to false gods and what the nonbeliever does perpetually with the whole array of normative concepts are equally coherent. This does not settle the weighty question of whether any existing person is divine. Neither does it settle whether a fully adequate ethical view must make reference to divine plans and commands. But it does give responsible theists and nonbelievers some badly needed common ground to get a conversation going. ${ }^{21}$

Jeffrey Stout

Department of Religion, 1879 Hall, Princeton University, Princeton, NJ 08544, USA

stout@princeton.edu

${ }^{21}$ I wish to thank David Fergusson and Chad Pecknold for the generosity and thoughtfulness of their reviews and Iain Torrance for kindly affording me this opportunity to respond. 